\title{
OPTIMIZATION OF PARAMETERS OF THE MOBILE MACHINE ADAPTIVE HYDRAULIC CIRCUIT
}

\author{
Yurii Buriennikov ${ }^{1}$, Leonid Kozlov ${ }^{1}$, Oana Rusu ${ }^{2}$, Viktor Matviichuk ${ }^{3}$, Volodymyr Pyliavets ${ }^{1}$, \\ Natalia Semychasnova ${ }^{1}$, Ioan Rusu ${ }^{2}$
}

\author{
${ }^{1}$ Vinnytsia National Technical University, 95 Khmelnytske Shose St., Vinnytsia, 21021, Ukraine \\ 2"Gheorghe Asachi" Technical University, 41 Dimitrie Mangeron Blvd., Iași, 700050, Romania \\ ${ }^{3}$ Vinnytsia National Agrarian University, Sonyachna 3, Vinnytsia, 21008, Ukraine
}

Corresponding author: Oana Rusu, oana.rusu@academic.tuiasi.ro

\begin{abstract}
Mobile machine hydraulic circuits tend to adopt electrohydraulics. Such hydraulic circuits are based on controlled pumps, modulated hydraulics, sensors and controllers. This allows adapting the hydraulic circuit operating modes to the changes of external conditions of the machine operation. Application of hydraulic circuits with electrohydraulics in mobile machines allows to use mobile machines efficiently with a high number of removable endangers, increases their performance and improves the quality of performed works. The authors propose an adaptive hydraulic circuit for a mobile machine. The operation process in the adaptive hydraulic circuit in static and dynamic modes is determined by the interaction of the pump controller and pressure differential control valves. The hydraulic system operation stability, its fast response and readjustment are determined by the controller parameters. It has been revealed that the main parameters affecting the dynamic characteristics of the hydraulic system are: throttle area $f_{0}$ and coefficient of $k_{z}$ amplifying the pump controller orifice, dampener area $f_{2}$ and coefficient of $k_{y}$ amplifying the pressure differential control valve orifice. These parameters affect the stability, controlling and readjustment time in the hydraulic circuit differently. A functional including the values of controlling time $t_{p}, \sigma$ controlling and losses $N_{y}$ in the pump controller was used as an optimization criterion. The optimization has been made according to the developed mathematical model applying the method developed by I. Sobol and R. Statnikov. During the optimization each controller parameter changed on 3 levels. 81 tests were made and the best combination of controller parameters for the optimization criterion was determined. The following hydraulic circuit operation values were reached under the optimal values of parameters $f_{0}=$ $1.0 \cdot 10^{-6} \mathrm{~m}^{2}, k_{z}=1.0 \cdot 10^{-3} \mathrm{~m}, f_{2}=1.2 \cdot 10^{-6} \mathrm{~m}^{2}, k_{y}=10 \cdot 10^{-3} \mathrm{~m}:$ $t_{p}=1.1 \mathrm{c}, \sigma=32 \%, N_{y}=0.82 \mathrm{~kW}$ that comply with the requirements towards hydraulic circuits of mobile machines.
\end{abstract}

Key words: mobile machine, adaptive hydraulic circuit, mathematical model, dynamic characteristics, optimization.

\section{INTRODUCTION}

The development trends of mobile machine hydraulic circuits are the transition to electro-hydraulic control, proportional hydraulic equipment and adjustable pumps [1-5]. Such hydraulic circuits enable to regulate values of pressures and flow rates to hydraulic motors in wide ranges. This creates an opportunity to ensure optimal speed of the actuating elements, and accordingly to increase the productivity of machines and the quality of work performed by them. Equipping of hydraulic circuits with electrohydraulic control with programmable controllers allows to provide adaptation of operating modes of hydraulic circuits to change of external conditions and loads. This enables to increase the accuracy of their work, reduce overload and power loss [6,7]. Mobile machines with electrohydraulic circuits are used in a large number of different operations subject to the use of replaceable actuating elements. The most common replaceable actuating elements for mobile machines are: excavator, crane and drilling equipment, loaders, hydraulic hammers [8]. The use of replaceable actuating elements in different types of operations requires specific control algorithms for the electrohydraulic circuit. For example, in auger drilling operations, it is necessary to maintain a certain ratio between the auger rotation speed and its feed. This is due to the fact that the rotation speed and feed of the auger determine the productivity of soil disruption during drilling. The auger rotation frequency determines the productivity of loose rock transportation to the surface. If the productivity of soil disruption by the auger exceeds the productivity of transportation, a soil compaction is formed in the working zone of the auger, which will stop the process of rock transportation by the auger. The ratio defined in work [9] has to be maintained between the rotation speed and its feed by the controller of the adaptive electrohydraulic circuit. Hydraulic circuits with electro-hydraulic control based on the use adjustable pumps include pump regulators and differential pressure valves. These controllers work simultaneously for one control 
object. In dynamic processes, complex processes of interaction take place between regulators, regulated pumps and the actuating element. They occur as unstable operating modes, large values of the adjustment and re-adjustment time, as well as power losses. To reduce the negative interaction developments of regulators in dynamic processes, it is necessary to optimize their parameters. A number of research works deals with the optimization of hydraulic circuits in mobile machines $[5,10]$. Determining the optimal parameters of hydraulic circuits provides a significant improvement in the performance of mobile machines. A number of research works present the optimization results for the structure and design parameters, where a significant improvement in energy performance [11], as well as in accuracy and speed [12] is achieved. There are works in which the complex criteria, including requirements for static, dynamic and energy characteristics, determine the optimal values for the design parameters of pump regulators and flow regulators that are part of adaptive electro-hydraulic circuits $[8,13]$.

The research objective is to determine the optimal parameters for pump regulators and differential pressure valves, which are part of the adaptive electro-hydraulic circuit of a mobile machine on the basis of a criterion that includes requirements for static, dynamic and energy characteristics.

\section{ADAPTIVE ELECTRO-HYDRAULIC CIRCUIT FOR MOBILE MACHINES}

We consider the operation of an adaptive electrohydraulic circuit for a mobile machine [14]. The hydraulic circuit includes (Figure 1): adjustable pump 1 , distributors 3,4 , hydraulic cylinder 5 , hydraulic motor 6, adjustable throttles 17,18 , valves 8,7 , controller 9, amplifiers 10, 11, sensors $12,13,14,15$, tank 16, and logic valve 28 . The hydraulic circuit operates as follows. The adjustable pump 1 supplies the working fluid to the hydraulic motor 6 through the adjustable throttle 17 , the valve 8 , the distributor 3 and simultaneously to the hydraulic cylinder 5 through the adjustable throttle 18, the valve 7 and the distributor 4 . The distributor 3 with manual control provides start, stop, and reverse of the hydraulic motor 6. The adjustable throttle 17 with electromagnetic control from the controller 9 provides a change in the feed value $Q_{n 1}$, supplied by the pump 1 to the hydraulic motor 6 . By changing the value of the area $f_{x 1}$ of the working window of the adjustable throttle, it is possible to control the rotation speed of the hydraulic motor 6 . The sensors 12 and 13 measure the pressure values at the inlet of the hydraulic motor 6 and transmits the corresponding signals to the controller 9. The working fluid from the pump 1 (feed $Q_{n 2}$ ) also enters the hydraulic cylinder 5 , determining the movement speed $v_{\mathrm{c}}$ of its piston. The sensors 14, 15 measure the pressure values at the inlet of the hydraulic motor 5 and transmit the corresponding signals to the controller 9. The controller 9 forms an algorithm for controlling adjustable throttles 17 and 18 based on signals from sensors $12,13,14$, and 15 . This algorithm provides the optimal ratio between the rotation speed $\omega_{m}$ and the piston movement speed $v_{c}$ of the hydraulic cylinder 4 . The pressure $p_{n 1}$ at the outlet of the pump 1 will be determined by the pressure $p_{m}$ or the pressure $p_{c}$ depending on their ratio. The larger pressure is fed to the adjustable pump 1 through the logic valve 28. The pressures $p_{m}$ and $p_{c}$ in turn depend on the value of the moment $M_{m}$ on the shaft of the hydraulic motor 6 and the value of the load value $T_{c}$ on the rod of the hydraulic cylinder 5 .

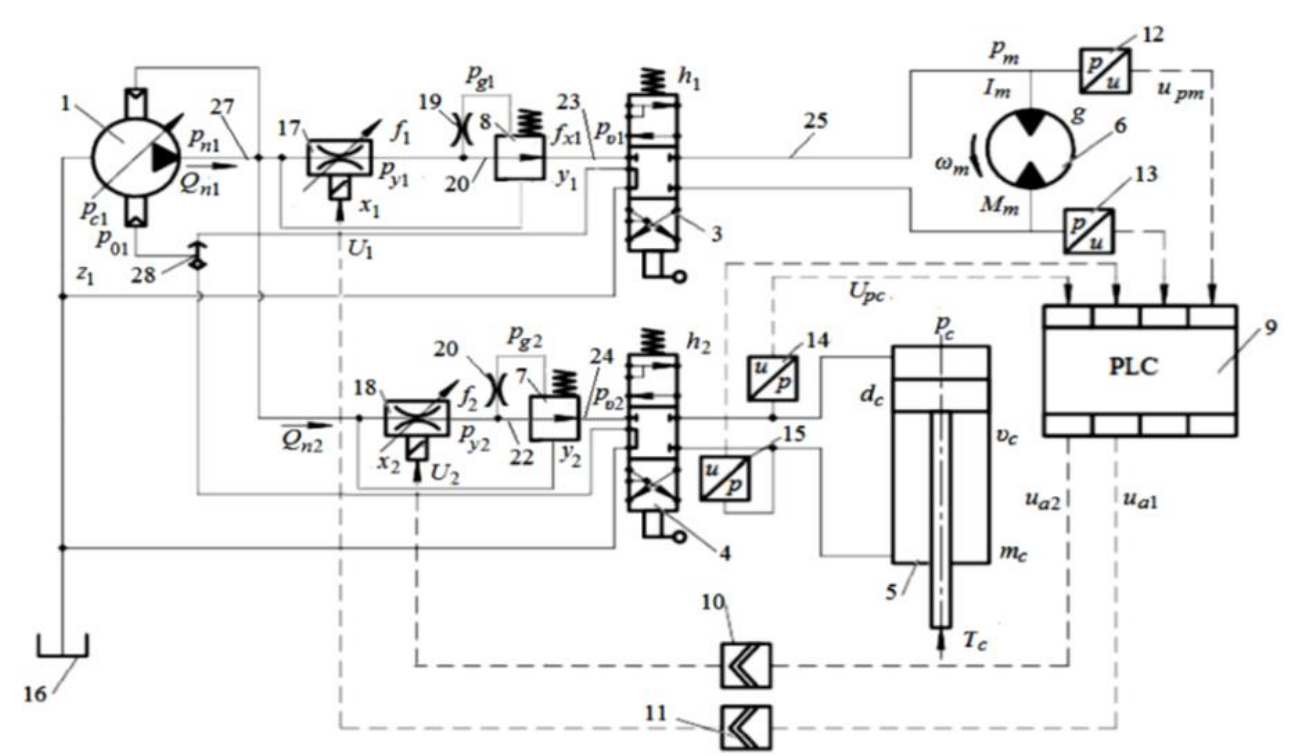

Fig. 1. Adaptive hydraulic circuit for a mobile machine 
In Figure 2 is presented the design model of drives for the drilling auger which is a replaceable actuating element on the BAM-2014 machine.

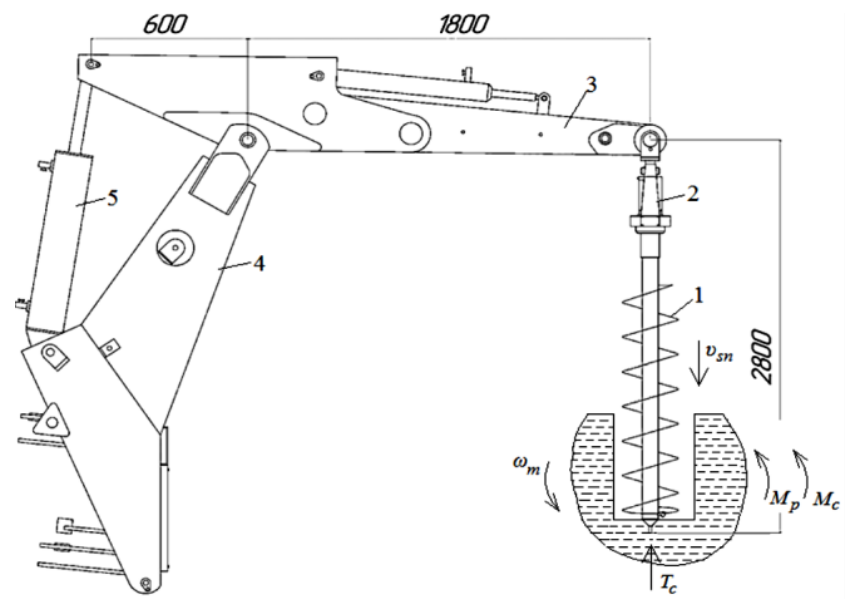

Fig. 2. Scheme of auger drives for drilling

The drilling auger 1 is rigidly connected to the shaft of hydraulic motor 2, which is mounted on the arm 3 of the excavator equipment. The auger drive is provided by a separate adjustable pump; the auger speed varies according to the controller signal supplied to the hydraulic motor drive distributor. Special adapters are used to install the hydraulic motor with an auger on the arm. The drilling auger feed is provided by the hydraulic cylinder 5 of the arm drive. The hydraulic cylinder 5 is driven by a separate adjustable pump.
The mathematical model of adaptive hydraulic circuit (see Figure 1 and Figure 2) includes the following equations. The equation for the flow of hydraulic lines: between adjustable pump 1 and adjustable throttles 17,18 , equation (1); between the adjustable throttles and differential pressure valves, equation (2); between the distributing valve 3 and the hydraulic motor 6, equation (4); between the distribution spool 4 and the hydraulic cylinder 5 , equation (3); between dampers and differential pressure valves, equations $(6,7)$; between the spool of the pump regulator 1 and the throttle, equation (7); between the damper and the plunger of the faceplate of pump 1, equation (8). The equation of moments acting on: the faceplate of pump 1, equation (9); the shaft of hydraulic motor 6, equation (12). The equation of forces acting on: pump regulator, equation (10); adjustable throttles, equation (14); differential pressure valve, equation (11). The equation of currents in control lines: from the pressure sensor 12 to the adjustable throttle 18 , equation (15); voltage equation on the electromagnet windings of adjustable throttles 17 and 18, equation (16). The equation of moments acting on arm 3 (Figure 2), equation (13). Dependence of the coefficient of compliance of the working fluid, rubber-metal pipes and the proportion of undissolved air, equation (17). Dependence of the cutting moment during drilling, equation (19) and axial force, equation (18), on the rotation frequency of the auger and its feed.

$$
\begin{gathered}
\frac{\pi d_{7}^{2}}{4} d_{8} k n_{1} t_{g} \gamma_{1}-k_{n} p_{n 1}=Q_{x 1}+Q_{x 2}+\mu k_{z} z_{1} \sqrt{\frac{2\left|p_{n 1}-p_{01}\right|}{\rho}} \operatorname{sign}\left(p_{n 1}-p_{01}\right)+\beta_{n} W_{n 1} \frac{d p_{n 1}}{d t} \\
Q_{x i}=Q_{y i}+\beta W_{y 1} \frac{d p_{y i}}{d t}+\mu f_{i} \sqrt{\frac{2\left|p_{y i}-p_{g i}\right|}{\rho}} \operatorname{sign}\left(p_{y 1}-p_{g 1}\right) \\
Q_{y i}=Q_{v i}+\beta W_{v i} \frac{d p_{v i}}{d t} \\
Q_{v 1}=\frac{2 \pi \omega_{m} q_{m}}{\eta_{1}}+\beta_{n} W_{m} \frac{d p_{m}}{d t} \\
Q_{v 2}=\frac{\pi d_{c} v_{s n} l_{1} \cos \alpha_{2}}{4 l_{1} \cos \alpha_{1} \cos \alpha_{3}}+\beta_{n} W_{c} \frac{d p_{c}}{d t} \\
\mu f_{i} \sqrt{\frac{2\left|p_{y i}-p_{g i}\right|}{\rho}} \operatorname{sign}\left(p_{y i}-p_{g i}\right)=\beta_{n} W_{g i} \frac{d p_{g i}}{d t}+\frac{\pi d_{y i}^{2}}{4} \cdot \frac{d y_{i}}{d t}+\left(A_{y} p_{g i}+B_{y} t^{\circ}+C_{y} \varepsilon_{b}^{2}\right) \\
\mu k_{z} z_{1} \sqrt{\frac{2\left|p_{n 1}-p_{01}\right|}{\rho}} \operatorname{sign}\left(p_{n 1}-p_{01}\right)=\beta W_{0} \frac{d p_{01}}{d t}+\mu f_{e} \sqrt{\frac{2\left|p_{01}-p_{e 1}\right|}{\rho}} \operatorname{sign}\left(p_{01}-p_{e 1}\right)+\mu f_{0} \sqrt{\frac{2 p_{01}}{\rho}} \\
\mu f_{e} \sqrt{\frac{2\left|p_{01}-p_{e 1}\right|}{\rho}} \operatorname{sign}\left(p_{01}-p_{e 1}\right)=\beta_{n} W_{e} \frac{d p_{e 1}}{d t}-f_{4} l \frac{d \gamma_{1}}{d t}-\left(A_{e} p_{e 1}+B_{e} t^{\circ}+C_{e} \varepsilon_{e}^{2}\right)
\end{gathered}
$$




$$
\begin{aligned}
& I_{1} \frac{d^{2} \gamma_{1}}{d t^{2}}=p_{n 1} f_{5} l-p_{e 1} f_{4} l-\frac{\pi \rho v_{k} d_{4} l_{4}}{\varepsilon_{0}} l^{2} \frac{d \gamma_{1}}{d t} \cos \gamma_{1}-\frac{\pi \rho v_{k} d_{5} l_{5}}{\varepsilon_{o}} l^{2} \frac{d \gamma_{1}}{d t} \cos \gamma_{1}+m_{0}+m_{1} Q_{n 1}+ \\
& +m_{2} p_{n 1}+m_{3} Q_{n 1}^{2}+m_{4} p_{n 1}^{2}+m_{5} p_{n 1} Q_{n 1} \\
& m_{p} \frac{d^{2} z_{1}}{d t^{2}}=p_{n 1} \frac{\pi d_{p}^{2}}{4}-p_{m} \frac{\pi d_{p}^{2}}{4}-\mathrm{c}\left(H_{p}+z_{1}\right)-\frac{\pi \rho v_{k} d_{p} l_{p}}{\varepsilon_{p}} \frac{d z_{1}}{d t} \\
& m_{y i} \frac{d y_{i}^{2}}{d t^{2}}=p_{g i} \frac{\pi d_{y i}^{2}}{4}-p_{y 1} \frac{\pi d_{y i}^{2}}{4}-c_{b}\left(H_{y i}+y_{i}\right)-\left(A_{g i}+B_{g i} p_{n i}-\frac{D_{g i}}{y_{i}}+\frac{E_{g i}}{y_{i}^{2}}\right)-\frac{\pi \rho v_{k} d_{y i} l_{y i}}{\varepsilon_{y i}} \frac{d y_{i}}{d t} \\
& I_{m} \frac{d \omega_{m}}{d t}=p_{m} q-b_{m} \omega_{m}-M_{m}-M_{p} \\
& I_{c} \frac{d^{2} \varphi_{c}}{d t^{2}}=p_{c} \frac{\pi d_{c}^{2}}{4} l_{1} \cos \alpha_{1}-\left(T_{c}+T_{p} \operatorname{sign} v_{s n}\right) l_{2} \frac{\cos \alpha_{2}}{\cos \alpha_{3}}-\left(\pi d_{c}\left(q_{0}+k_{q} p_{c}\right)-\pi d_{s}\left(q_{0}+k_{q} p_{p}\right)\right) . \\
& \cdot l_{1} \cos \alpha_{1}-\sum M_{0 i} \\
& U_{1} k_{m 1}=c_{1}\left(H_{1}+x_{1}\right) ; U_{2} k_{m 2}=c_{2}\left(H_{2}+x_{2}\right) \\
& p_{m} k_{4} F_{n} F_{k}\left(U_{p m}\right)=i_{m 2} ; \quad F_{k 1} k_{n}=i_{m 1} \\
& U_{1}=L e \frac{d i_{m 1}}{d t}+i_{m 1} R e ; \quad U_{2}=L e \frac{d i_{m 2}}{d t}+i_{m 2} R e \\
& \beta_{n}=\frac{1}{E_{p}}+\frac{d_{m p}}{\delta_{m p} E_{m p}(p)} ; \quad E_{p}=\frac{1}{\beta_{p}}=E_{p 0}=\frac{W_{f} / W_{a}+1}{W_{f} / W_{a}+\left(E_{p 0} p_{0}\right) / p^{2}} \\
& T_{c}=k_{n} \frac{2 e Q}{\omega_{m} \sqrt{R_{1}^{2}+R_{2}^{2}}} \\
& M_{m}=C_{1}\left(v_{s n} \frac{2 \pi}{z \omega_{m}}\right)^{C_{2}}\left(\frac{\pi R_{c}^{2} v_{s n}}{\omega_{m}}\right)
\end{aligned}
$$

where:

$p_{n 1}, p_{m}, p_{c}, p_{y i}, p_{0}, p_{e}[\mathrm{MPa}]-$ pressures at the outlet of the pump 1, inlets of the hydraulic motor 6 and the hydraulic cylinder 5, valve outlets, in the control circuit of the pump 1, in the servo cylinder of pump 1;

$z_{i}, x_{i}, y_{i}[\mathrm{~m}]-$ position coordinates of the pump regulator, adjustable throttles, differential pressure valves;

$\omega_{m}\left[\mathrm{~s}^{-1}\right], v_{c}[\mathrm{~m} / \mathrm{s}]$ - frequency of shaft rotation of the hydraulic motor 6 and piston speed of the hydraulic cylinder 5;

$\gamma_{1}[\mathrm{rad}]$ - rotation angle of the faceplate of pump 1; $f_{0}, f_{e}, f_{x i}, F_{7}\left[\mathrm{~m}^{2}\right]$ - area of throttles in the pump regulator, area of pool valves of the adjustable throttles, area of pump pistons;

$d_{c}, d_{s}, d_{y i}, d_{z}, d_{8}[\mathrm{~m}]$ - diameters of the piston and rod of hydraulic cylinder 5, pressure relief valves, pump regulator, diameter of the contact circle of pump pistons with the pump faceplate;

$i_{m i}[\mathrm{~A}]$ - current magnitude in the windings of electromagnets; $k_{m i}\left[\frac{\mathrm{kg} \cdot \mathrm{m}}{\mathrm{s}^{2} \cdot \mathrm{V}}\right], k_{4}\left[\frac{\mathrm{V} \cdot \mathrm{m} \cdot \mathrm{s}^{2}}{\mathrm{~kg}}\right], k_{1}-$ coefficients of force proportionality of electromagnets of adjustable throttles, pressure sensors, number of pistons in the pump 1;

Le $[\mathrm{H}], \operatorname{Re}[\Omega]$ - inductance and active resistance of electromagnet windings;

$c_{z}, c_{y i}[\mathrm{~N} / \mathrm{m}]$ - spring tension of pump regulator and pressure drop valves;

$T_{\mathrm{c}}[N], M_{m}[\mathrm{~N} \cdot \mathrm{m}]$ - values of the reduced loads on the rod of hydraulic cylinder 5 and the shaft of hydraulic motor 6;

$T_{p}[N], M_{p}[\mathrm{~N} \cdot \mathrm{m}]$ - force and moment of friction on hydraulic motors;

$\mu$ - flow coefficient through throttle and spool elements;

$\rho\left[\mathrm{kg} / \mathrm{m}^{3}\right]$ - density of the working fluid; $l$ - arm of servo cylinders of pump 1 ;

$I, I_{m}\left[\mathrm{~kg} \cdot \mathrm{m}^{2}\right]$ - inertia moments of pump faceplate and moving elements driven by the shaft of hydraulic motor 6

$m_{c}[\mathrm{~kg}]-$ mass of moving elements driven by the rod of hydraulic cylinder 5; 
$W_{n 1}, W_{0}, W_{m}, W_{y i}, W_{c}, W_{e} \quad\left[\mathrm{~m}^{3}\right]-$ volumes of hydraulic lines at the outlet of pump 1, in the pump regulator, at the inlet of hydraulic motor 6 , at the outlet of the pressure drop valves, at the inlet to hydraulic cylinder 5, between the throttle and the servo cylinder of pump 1;

$n_{n}\left[\mathrm{~s}^{-1}\right]$ - shaft speed of pump 1 ;

$F_{k}\left(U_{p m}\right)$ - transfer function of the controller for the signal supplied to the amplifier 10;

$F_{n}$ - transfer function of amplifiers;

$F_{k 1}$ - transfer function of the controller for the signal transmitted to amplifier 11 ;

$H_{z}, H_{y 1}, H_{y 2} \quad$ [m] - pre-compression of pump regulator springs and differential pressure valves;

$m_{0}[\mathrm{~N} \cdot \mathrm{m}]$,

$m_{1}\left[\frac{\mathrm{kg}}{\mathrm{s} \cdot \mathrm{m}}\right], m_{2}\left[\mathrm{~m}^{3}\right], m_{3}\left[\frac{\mathrm{kg}}{\mathrm{s} \cdot \mathrm{m}^{4}}\right], m_{4}\left[\frac{\mathrm{m}^{4} \cdot \mathrm{s}^{2}}{\mathrm{~kg}}\right], m_{5}\left[\frac{\mathrm{kg} \cdot \mathrm{m}}{\mathrm{s}}\right]$

- dependence coefficients of resistance moment on the faceplate of pump 1 on feed rate and pressure;

$\beta_{p}\left[\frac{\mathrm{m} \cdot \mathrm{s}^{2}}{\mathrm{~kg}}\right]$ - reduced factor of pliability of the gasliquid mixture;

$\beta_{n}\left[\frac{\mathrm{m} \cdot \mathrm{s}^{2}}{\mathrm{~kg}}\right]$ - reduced factor of of pliability of rubbermetal pipelines and gas-liquid mixture;

$q_{m}\left[\mathrm{~m}^{3}\right]$ - working volume of hydraulic motor 6 ;

$U_{1}, U_{2}[\mathrm{~V}]$ - voltage values on the electromagnets of adjustable throttles 17, 18;

$U_{a 1}, U_{a 2}[\mathrm{~V}]$ - voltage values at the inputs of amplifiers 10 and 11 ;

$E_{p 0}, E_{p}, E_{m p}(p)\left[\frac{\mathrm{kg}}{\mathrm{m} \cdot \mathrm{s}^{2}}\right]-$ modulus of the working fluid elasticity, the reduced modulus of elasticity of the gas-liquid mixture and rubber-metal pipelines;

$\delta[\mathrm{m}]$ - wall thickness of the pipeline;

$W_{f}\left[\mathrm{~m}^{3}\right]$ - volume of liquid in the gas-liquid mixture at value of pressure p;

$W_{a}\left[\mathrm{~m}^{3}\right]$ - volume of gas in the gas-liquid mixture at atmospheric pressure;

$A_{y}\left[\frac{\mathrm{m}^{4} \cdot \mathrm{s}}{\mathrm{kg}}\right], B_{y}\left[\frac{\mathrm{m}^{3}}{\mathrm{~s} \cdot \mathrm{grad}}\right], C_{y}\left[\frac{\mathrm{m}}{\mathrm{s}}\right]-$ coefficients in the dependences of leaks from the control chamber of the pressure drop valve;

$A_{e}\left[\frac{\mathrm{m}^{4} \cdot \mathrm{s}}{\mathrm{kg}}\right], B_{e}\left[\frac{\mathrm{m}^{3}}{\mathrm{~s} \cdot \mathrm{grad}}\right], C_{e}\left[\frac{\mathrm{m}}{\mathrm{s}}\right]-$ coefficients in the dependences of leaks from the chamber of the pump servo cylinder;

$v_{k}\left[\mathrm{~m}^{2} / \mathrm{s}\right]$ - kinematic viscosity coefficient of the working fluid;

$\varepsilon_{0}, \varepsilon_{p}, \varepsilon_{y 1}, \varepsilon_{y 2}[\mathrm{~m}]$ - radial gaps between the spool valves and servo cylinder housings, pump regulator, differential pressure valves;

$l_{4}, l_{5}, l_{p}, l_{y 1}, l_{y 2}[\mathrm{~m}]$ - contact length of spool valves and housings in pump servo cylinders, pump regulator, differential pressure valves;

$b_{m 1}\left[\mathrm{~kg} \cdot \mathrm{m}^{2}\right]$ - damping coefficient of the hydraulic motor shaft; $q_{0}\left[\mathrm{~kg} / \mathrm{s}^{2}\right]-$ specific friction force in the hydraulic cylinder;

$k_{q}[\mathrm{~m}]-$ coefficient of specific friction force in the hydraulic cylinder;

$C_{1}$ - parameter that depends on the properties of the soil;

$C_{2}$ - parameter that depends on the type of tool;

$z$ - number of cutting blades of the tool;

$R_{c}[\mathrm{~m}]$ - pit diameter;

$R_{1}[\mathrm{~m}]$ - diameter of the auger base;

$k_{n}$ - proportionality factor for axial force.

Equations of mathematical model were solved by utilizing the Rosenbrock numerical method in MATLAB-Simulink environment with absolute accuracy of $\varepsilon_{a}=10^{-6}$ and relative accuracy of $\varepsilon_{6}=10^{-3}$.

\section{RESEARCH RESULTS AND OPTIMIZATION OF PARAMETERS FOR REGULATORS}

The required dynamic characteristics of an adaptive hydraulic circuit are provided by a selection of the corresponding values of constructive parameters of regulators. The dynamic characteristics of an adaptive hydraulic circuit are most affected by the parameters of the pump regulator, differential pressure valve and controller settings. The influence of the main parameters of regulators on dynamic characteristics is researched. The parameters varied in the following ranges: $\mathrm{k}_{\mathrm{z} 1}=(1 \ldots 7) \cdot 10^{-3} \mathrm{~m} ; \mathrm{b}_{\mathrm{z} 1}=(5 \ldots 200) \mathrm{kg} / \mathrm{s} ; \mathrm{f}_{01}$ $=(1 \ldots 5) \cdot 10^{-6} \mathrm{~m}^{2} ; \mathrm{d}_{\mathrm{p}}=(5 \ldots 8) \cdot 10^{-3} \mathrm{~m} ; \mathrm{f}_{\mathrm{e}}=(1 \ldots 3) \cdot 10^{-}$ ${ }^{6} \mathrm{~m}^{2} ; k_{y 2}=(5 \ldots 30) \cdot 10^{-3} \mathrm{~m} ; \mathrm{f}_{2}=(0.8 \ldots 2.0) \cdot 10^{-6} \mathrm{~m}^{2}$; $d_{y 2}=(10 \ldots 20) \cdot 10^{-3} \mathrm{~m}$.

In the process of research, the change of design parameters of regulators was carried out as follows. One of the parameters varied in the corresponding range at three levels: minimum, average and maximum. In this case, all other parameters had constant values corresponding to their average values from the defined ranges. According to the calculated dependences of the variables $p_{m}, p_{c}, p_{n 1}, \omega_{m}, v_{c}$ from time, the time for adjustment and re-adjustment was determined. The adjustment time $t_{p}$ was taken equal to the moment of entry of the variable $p_{n 1}$ into the corridor $\pm 5 \%$ of value $p_{n 1}$ from the set value at the end of the transition process. The re-adjustment $\sigma$ was determined as a dependence of $p_{n 1}$ time.

In Figure 3(a), the influence of parameters $f_{2}, d_{y 2}$, $k_{y 2}$ of the pressure drop valve 7 on the value of adjustment time $t_{p}$ is presented. Increasing the value of area $f_{2}$ of throttle 28 increases the adjustment time $t_{p}$, and increasing the value of the diameter $d_{y 2}$ and the gain constant $k_{y 2}$ of the working window of the differential pressure valve 7 reduces the adjustment time $t_{p}$. If it is necessary to reduce the control time $t_{p}$ in the adaptive hydraulic circuit, the value of $f_{2}=$ 
$(0.6 \ldots 0.8) \cdot 10^{-6} \mathrm{~m}^{2}$, the values of $d_{y 2}=(16 \ldots 20) \cdot 10^{-3}$ $\mathrm{m}$, and the value of $k_{y 2}=(25 \ldots 30) \cdot 10^{-3} \mathrm{~m}$ should be selected. In Figure 3(b) the influence of parameters $f_{e}, f_{01}, k_{z 1}$ of pump regulator 1 on the adjustment time $t_{p}$ is presented. Increasing the throttle area of $f_{e}$ increases the adjustment time $t_{p}$, and increasing the gain constant $k_{z 1}$ of the working window of regulator reduces the adjustment time of the regulator $t_{p}$. The value of the throttle area $f_{01}$ should be chosen optimal from the considered range. If it is necessary to reduce the adjustment time $t_{p}$, it is recommended to choose the following values of the regulator parameters of pump $1 f_{e}=(1 \ldots 2) \cdot 10^{-6} \mathrm{~m}^{2}, k_{z 1}=$ $(3 \ldots .5) \cdot 10^{-3} \mathrm{~m}, f_{01}=(1.8 \ldots 3.0) \cdot 10^{-6} \mathrm{~m}^{2}$.

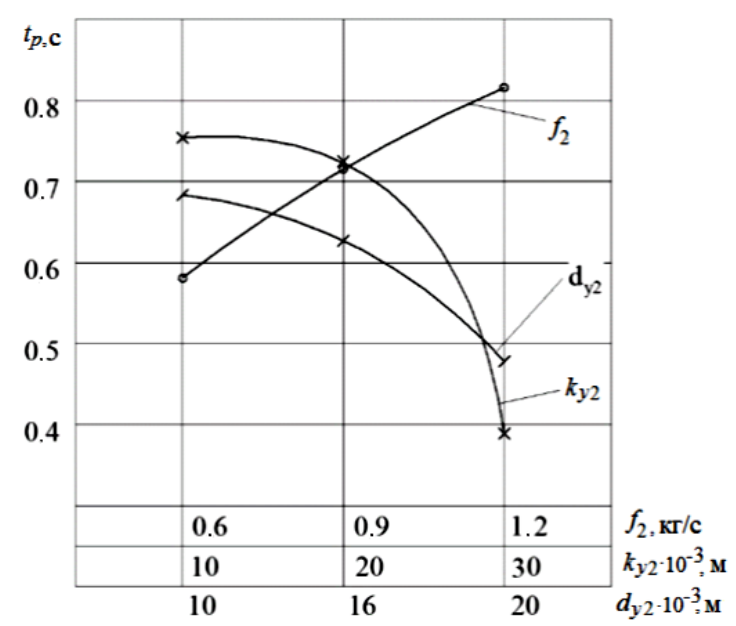

(a)

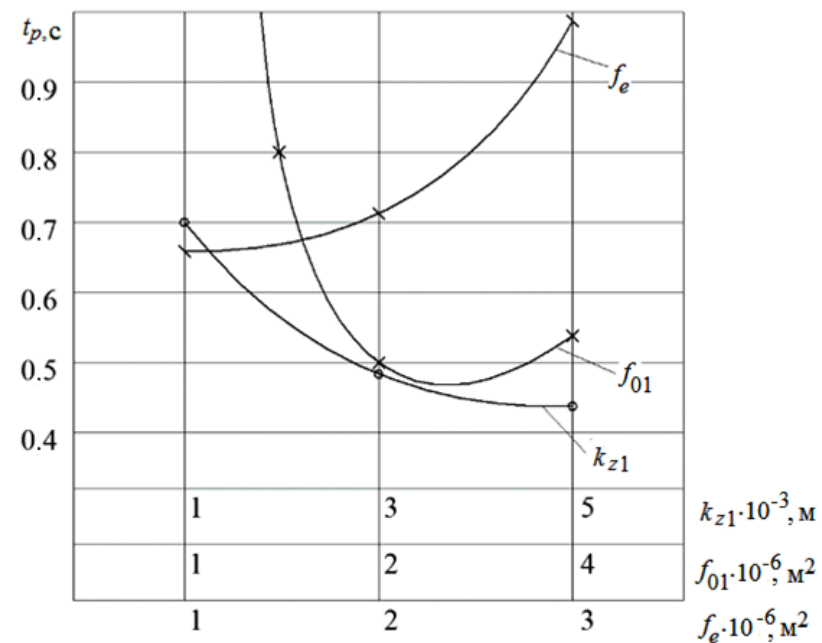

(b)

Fig. 3. Influence of parameters of pressure difference valves (a) and pump regulator (b) on adjustment time in adaptive hydraulic circuit

In Figure 4(a) is presented the influence of parameters $f_{2}, d_{y 2}, k_{y 2}$ of the pressure drop valve 7 on the value of re-adjustment time $\sigma$ according to pressure $p_{n 1}$. Increasing the value of area $f_{2}$ of throttle 28 increases the value of readjustment $\sigma$, and increasing the value of diameter $d_{y 2}$ reduces the value of readjustment $\sigma$. The effect of gain constant $k_{y 2}$ on readjustment $\sigma$ is negligible. If it is necessary to reduce the value of readjustment $\sigma$, the value of $f_{2}=(0.6 \ldots 0.8) \cdot 10^{-6} \mathrm{~m}^{2}, d_{y 2}=(16 \ldots 20) \cdot 10^{-3} \mathrm{~m}, k_{y 2}=$ $=(25 \ldots 30) \cdot 10^{-3} \mathrm{~m}$ should be selected.

In Figure 4(b), the influence of parameters $f_{e}, f_{01}$, $k_{z 1}$ of pump regulator 1 on the re-adjustment value $\sigma$ according to pressure $p_{n 1}$. Increasing the throttle area $f_{e}$ and gain constant $k_{z 1}$ increases the value of readjustment $\sigma$, and increasing the throttle area $f_{01}$ decreases the value $\sigma$. If it is necessary to reduce the value of readjustment $\sigma$, the following values of the controller parameters of pump $1 f_{e}=(2 \ldots 3) 10^{-6} \mathrm{~m}^{2}$, $k_{z 1}=(1 \ldots 3) \cdot 10^{-3} \mathrm{~m}, f_{01}=(3 \ldots 4) \cdot 10^{-6} \mathrm{~m}^{2}$ should be selected.

The optimization of parameters for regulators according to the optimization criterion, which includes several indicators has been carried out for the adaptive hydraulic circuit.

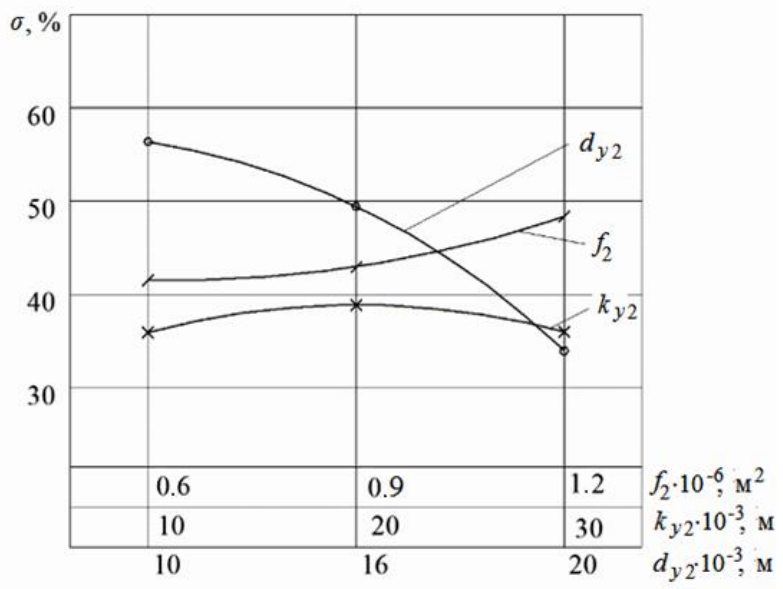

(a)

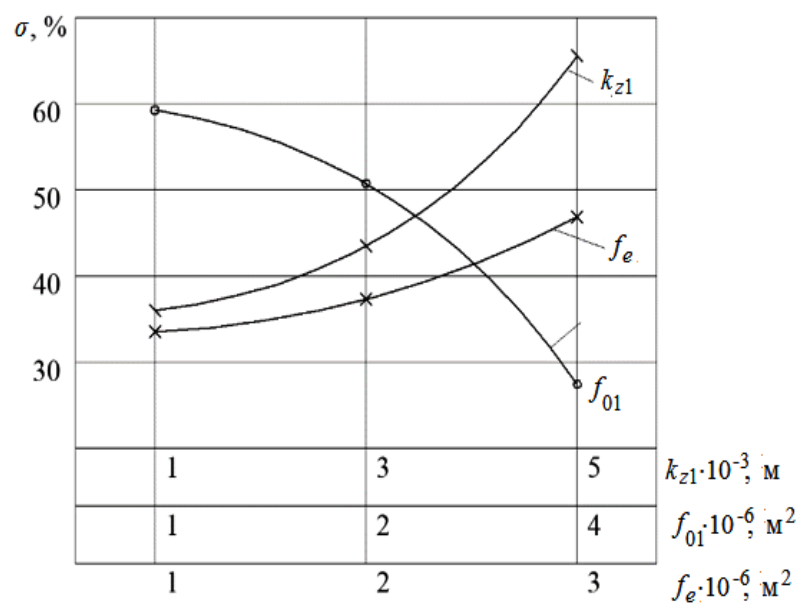

(b)

Fig. 4. Influence of parameters of pressure difference valve (a) and pump regulator (b) on readjustment value in adaptive hydraulic circuit

The optimization criterion includes 3 indicators: adjustment time (weight factor $k_{1}=0.3$ ); readjustment 
of the pump outlet pressure (weighting factor $k_{2}=$ 0.3 ); power loss in the pump controller (weighting factor $k_{3}=0.4$ ):

$$
k_{0}^{\prime}=k_{1} \frac{t_{p}}{t_{p}^{\max }}+k_{2} \frac{\sigma}{\sigma^{\max }}+N_{y} \frac{N_{y}}{N_{y}^{\max }}
$$

Optimization parameters and ranges of their change are presented in Table 1.

Table 1. Values of regulator parameters in optimization process

\begin{tabular}{|l|c|c|c|c|}
\hline \multicolumn{1}{|c|}{ Parameters } & Designation & $\min$ & $\operatorname{mdl}$ & $\max$ \\
\hline Pump regulator throttle area & $f_{0} \cdot 10^{-6}, \mathrm{~m}^{2}$ & 1.0 & 1.5 & 2.0 \\
Gain factor of pump regulator spool & $k_{z} \cdot 10^{-3}, \mathrm{~m}$ & 1.0 & 4.0 & 7.0 \\
Differential pressure valve spool damper & $f_{2} \cdot 10^{-6}, \mathrm{~m}^{2}$ & 0.8 & 1.0 & 1.2 \\
Gain factor of differential pressure valve spool & $k_{y} \cdot 10^{-3}, \mathrm{~m}$ & 10 & 25 & 40 \\
\hline
\end{tabular}

Table 2. Optimization calculated results

\begin{tabular}{|c|c|c|c|c|c|c|c|c|c|c|c|}
\hline $\begin{array}{c}\text { Experiment } \\
\text { number }\end{array}$ & $\begin{array}{c}f_{0} \cdot 10^{-6} \\
\mathrm{~m}^{2}\end{array}$ & $\begin{array}{c}k_{z} \cdot 10^{-3} \\
\mathrm{~m}\end{array}$ & $\begin{array}{c}f_{2}, 2 \cdot 10^{-6} \\
\mathrm{~m}^{2}\end{array}$ & $\begin{array}{c}k_{y} \cdot 10^{-3} \\
\mathrm{~m}\end{array}$ & $\begin{array}{c}t_{p} \\
\mathrm{~s}\end{array}$ & $\begin{array}{c}\sigma \\
\%\end{array}$ & $\begin{array}{c}N_{y} \\
\mathrm{~W}\end{array}$ & $k_{1} \frac{t_{p}}{t_{p}^{\max }}$ & $k_{2} \frac{\sigma}{\sigma^{\max }}$ & $k_{3} \frac{N_{y}}{N_{y}^{\max }}$ & $k_{0}^{\prime}$ \\
\hline 1 & 1.0 & 1 & 1.2 & 10 & 1.10 & 32 & 820 & 0.21 & 0.21 & 0.12 & 0.54 \\
7 & 1.0 & 4 & 0.8 & 10 & 1.25 & 44 & 839 & 0.25 & 0.29 & 0.12 & 0.66 \\
19 & 1.0 & 7 & 1.2 & 10 & 1.50 & 40 & 820 & 0.30 & 0.27 & 0.12 & 0.69 \\
30 & 1.5 & 1 & 1.2 & 40 & 1.00 & 30 & 1770 & 0.20 & 0.19 & 0.26 & 0.65 \\
35 & 2.0 & 4 & 1.2 & 10 & 1.08 & 30 & 2645 & 0.20 & 0.20 & 0.39 & 0.79 \\
\hline
\end{tabular}

The working processes in the adaptive hydraulic circuit at combination of all regulator parameters which changed at three levels were researched. A total of 81 experiments were performed. The optimization criterion $k_{0}^{\prime}$ is calculated for each experiment; for some experiments it is presented in Table 2 .

The optimal combination of regulator parameters has been found at which $k_{0}^{\prime}=0.54$ has the minimum value: $f_{2}=1.2 \cdot 10^{-6} \mathrm{~m}^{2}, k_{y 2}=10 \cdot 10^{-3} \mathrm{~m}, k_{z}=1.0 \cdot 10^{-3}$ $\mathrm{m}, f_{0}=1.0 \cdot 10^{-6} \mathrm{~m}^{2}$, with $t_{p}=1.1 \mathrm{~s}, \sigma==32 \%, N_{y}=$ $820 \mathrm{~W}$.

Comparison of transient processes calculated with the use of the mathematical model for combining the parameters of regulators before and after optimization is shown in Figure 5.

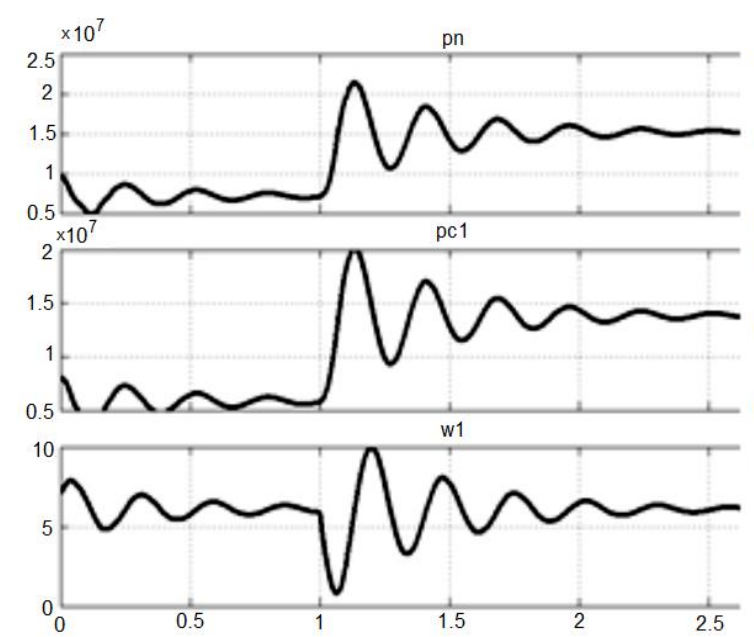

(a)

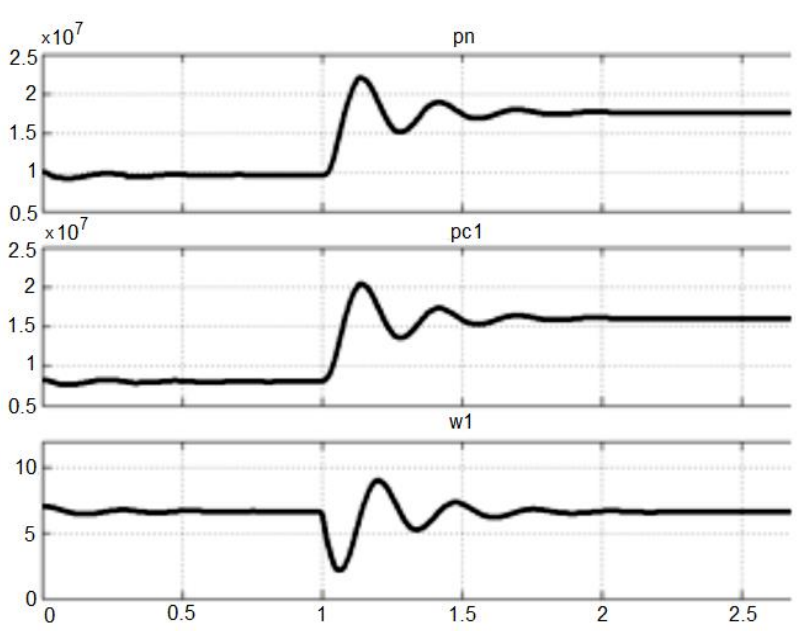

(b)

Fig. 5. The calculated transition process at the initial combination of parameters (a), at the optimal one (b)

\section{CONCLUSIONS}

The optimization has been made according to the developed mathematical model applying the method developed by I. Sobol and R. Statnikov. During the optimization each controller parameter changed on 3 levels. 81 tests were made and the best combination of controller parameters for the optimization criterion was determined. The following hydraulic circuit operation values were reached under the optimal values of parameters $f_{0}=1.0 \cdot 10^{-6} \mathrm{~m}^{2}, k_{z}=1.0 \cdot 10^{-3} \mathrm{~m}$, $f_{2}=1.2 \cdot 10^{-6} \mathrm{~m}^{2}, k_{y}=10 \cdot 10^{-3} \mathrm{~m}: t_{p}=1.1 \mathrm{~s}, \sigma=32 \%$, $N_{y}=820 \mathrm{~W}$ that comply with the requirements towards hydraulic circuits of mobile machines.

\section{REFERENCES}

1. Strutynsky V, Hurzhii A, Kozlov L., (2019), Determination of static equilibrium conditions of a 
mobile terrestrial robotic complex, Naukovyi Visnyk Natsionalnoho Hirnychoho Universytetu, 5, pp. 79-96. 2. Petrov O, Kozlov L, Lozinskiy D, Piontkevych O., (2020), Improvement of the Hydraulic Units Design Based on CFD Modeling Mechanical Engineering book series, (LNME) XXII, pp. 653-660.

3. Kozlov L, Polishchuk L, Korinenko M, Horbatiuk M, Orazalieva S, Ussatova O., (2019), Experimental research characteristics of counterbalance valve for hydraulic drive control system of mobile machine, Przeglad Elektrotechniczny, 4, pp. 104-109.

4. Petrov O, Slabkyi A, Vishtak I, Kozlov L., (2020), Mathematical Modeling of the Operating Process in LS Hydraulic Drive Using MatLab GUI Tools, DSMIE 2020: Advances in Design, Simulation and Manufacturing III, Lecture Notes in Mechanical Engineering 1-11 pp 52-62.

5. Panchenko I, Voloshyna A, Panchenko I, Voloshyn A., (2020), Design of mechatronic systems with given initial characteristics, Proceedings of the Tavriya State Agrotechnological University 4 pp 18-35.

6. Burennikov Y, Kozlov L, Pyliavets V, Piontkevich O., (2017), O Mechatronics hydraulic drive with regulator based on artificial neural network IOP Conf. Ser.: Mater. Sci. Eng. 209:012071.

7. Sidorenko VS, Grishchenko VI, Rakulenko SV, Poleshkin MS., (2017), Adaptive hydraulic drive with volumetric control of the tool feed of the technological machine, Bulletin of Donetsk State Technical University 2 pp 88-98.

8. Kozlov L., (2015), Scientific foundations for designing the systems of manipulator hydraulic drives with an adaptive neural network-based controllers for mobile working machines (National Technical University of Ukraine «Kyiv Polytechnic Institute» of the Ministry of Education of Ukraine Kyiv).

9. Kazachenko GV, Nagorskiy AV, Basalay GA, (2012), Research of auger drilling process. Part 1 Formation of mathematical model of the work flow in steady-state drilling, Mining mechanics and mechanical engineering, 3, pp. 65-74.

10. Bukhtoyarov L, Popikov I, Sidorov A., (2010), Parameters Optimization of Hydraulic Actuator Damper for Boom Hoisting Mechanism of Forest Manipulator, Journal of Forest Science, 6, pp, 102106.

11. Dong W, Kaiyuan L., (2018), Design optimization of hydraulic energy storage and conversion system for wave energy converters, Protection and Control of Modern Power Systems, 3(7), pp 1-9.

12. Hongsheng L, Xinghai W, Zurui C, Jun Y, (2018), Optimal Design of Hydraulic System Parameters for Vector Propeller in Underwater
Robot, IOP Conf. Ser.: Mater. Sci. Eng., 452(4):042072.

13. Kozlov L, Bogachuk V, Bilichenko V, Tovkach A, Gromaszek K, Sundetov S, (2018), Determining of the optimal parameters for a mechatronic hydraulic drive, Proc. SPIE, Photonics Applications in Astronomy, Communications, Industry, and HighEnergy Physics Experiments, 10808 pp 61-71.

14. Kozlov L, Buriennikov Y, Piliavets V, Kotyk S, (2020), Adaptive hydraulic system, Patent 144036 Ukraine IPC E02F 9/22 F15B 13/06 No. u202002212 $165 \mathrm{p}$.

Received: March 25, 2021 / Accepted: December 20, 2021 / Paper available online: December 25, 2021 (C) International Journal of Modern Manufacturing Technologies 